\title{
Dysfunctional MCC under legal threat
}

\author{
The dysfunctional Medicines Control \\ Council (MCC), which has registered \\ less than half of all medicine \\ applications to it over the past 7 years, \\ has become a life-threatening risk to \\ patients and is now under legal threat \\ from stakeholders.
}

This emerged from an urgent letter sent to health minister, Dr Aaron Motsoaledi, and copied to MCC registrar, Ms Mandisa Hela, and all key government officials by the Southern African HIV Clinicians Society last month.

Ironically it comes just as the special task team headed by Benguela Health's Dr Nicholas Crisp completed a full audit of the backlog of 4000 medicines and put in place urgent measures to fast track critically needed registrations.

Crisp told Izindaba that by June all the administrative paperwork would be completed and 12 full-time evaluators would begin working on prioritised $\mathrm{HIV}$, TB, cancer and cardiovascular medicines.

'Once the multi-year backlogs are cleared, we need to set a timeframe of what (in future) is a reasonable timeframe for approval or denial of a medicine so we can define what a backlog is,' he said, stressing that any future political interference in the MCC would soon be almost impossible.

HIV Clinicians Society president, Dr Francois Venter, said in his letter that he'd been 'repeatedly approached' by HIV researchers, government health officials, international aid agencies, donors, pharmaceutical companies and activists expressing 'intense frustration' with the MCC's slow registration, especially of antiretrovirals (ARVs).

'Several of these individuals have indicated to me that they are considering resorting to legal action, as all other remedies, including repeated correspondence, have failed to draw a response or an explanation from the MCC.'

Venter listed a number of drugs that needed to be prioritised for children and adults and urged Motsoaledi to facilitate their fast tracking to treat
TB and other common opportunistic infections. These drugs included all fixed-dose combinations, especially those that will be on the State's first-line regimen, generic versions of some of the ARVs, darunavir, raltegravir, etravirine, and generic abacavir.

\section{Blocking more effective ARV roll-out}

If this was not done 'immediately', the government would be unable to issue a competitive tender for fixed-dose combinations in April, further delaying patient access to drugs that are easier to take and require less pharmacy time.

Any further delays would also mean compromising competition between pharmaceutical companies, with managed care organisations, medical aids and private patients having to pay more than they should.

'Several of these individuals
have indicated to me
that they are considering
resorting to legal action, as
all other remedies, including
repeated correspondence,
have failed to draw a
response or an explanation
from the MCC.'

A top Izindaba source revealed that the tender deadline will now almost certainly be put back to facilitate the MCC process (without which no tender can take place).

Venter's letter said that what appeared to be a blocking of access to lifesaving medication was 'simply unacceptable'.

'HIV remains an absolute public health emergency for South Africa, with almost half of all deaths due to the disease and over a million patients on ARVs.'

The new Department of Health HIV treatment guidelines strive to improve the selection of ARVs and the tender process while the private sector is seeking to expand access to drugs for people with resistance.
In both these cases, the single obstacle to obtaining affordable access to medicine appears to be the MCC registration process, as some dossiers have been before the MCC for years,' Venter wrote.

'I suggest you instruct your acting DG to place this issue on the next MCC meeting's agenda, scheduled for 19 March 2010, for immediate attention and action,' he added.

He asked for a 'formal and urgent response' from the MCC after the meeting.

Speaking hours before attending the 19 March meeting, Crisp said 'virtually everything on the agenda is urgent and serious'.

'I'm comfortable that everything possible will get done in the next 5 - 6 weeks. Many drugs have already been tabled with relevant committees and we've gone out of our way to ensure that every new HIV and TB drug is included because of the upcoming tender,' he added.

The process would be nowhere close to where it now is were it not for erstwhile health minister Barbara Hogan appointing Crisp to head the special task team late last year.

Motsoaledi told Parliament in early December last year that a team of 12 technical assistants and 24 clerks had audited the entire backlog and clinically evaluated nearly 800 medicines, spending around R13.5 million.

He said the 7-year backlog, which at one stage stood at over 4000 medicines, including HIV/ AIDS, cancer, TB, diabetes and antibiotic drugs, would take another 24 months to clear.

Crisp explained that some of the technical assistants had the expertise for conversion to full-time evaluators, but emphasised that his dozen evaluators were not to be confused with the technical assistants of whom Motsoaledi spoke.

Not all the evaluators were experts in all the drugs being applied for, 'so we'll still be dependent on outsiders in part'. 
Every evaluator had been asked to assess their current work loads so that the MCC could have realistic expectations of what they were capable of and adjust accordingly.

\section{Dire economic implications}

While the new initiative was welcomed by the industry and clinicians, the chairman of the trade association, Stavros Nicolaou, estimated that a generic medicine market worth R1.2 billion could not be tapped into because of the delays.

The process would be
nowhere close to where
it now is were it not for
erstwhile health minister
Barbara Hogan appointing
Crisp to head the special
task team late last year.

Of the 5300 medicine applications made in the country since 2002, less than half had been registered.

Crisp said that he was aware of the pressure being put on clinicians by the drug companies, but added, 'the real pressure we need to assess is do we have patients needing them?'

In response to questions in Parliament Motsoaledi said that in 2008, 5 of 748 medicines were registered while last year just 2 of 281 applications were registered.

He explained that the backlog was due to a 'technical problem' with an electronic data management system, plus a lack of staff.

Another 'significant failing' was the grossly inadequate tracking of a huge amount of paper associated with applications, he said.

Crisp said the single biggest problem was that the MCC was 'grossly understaffed', with $99 \%$ of its evaluators external, being paid a 'piddly hour rate (about R269 per hour)', while political interference had been rife.

'You won't get a professional to give all their private time to earn that kind of money,' he observed.

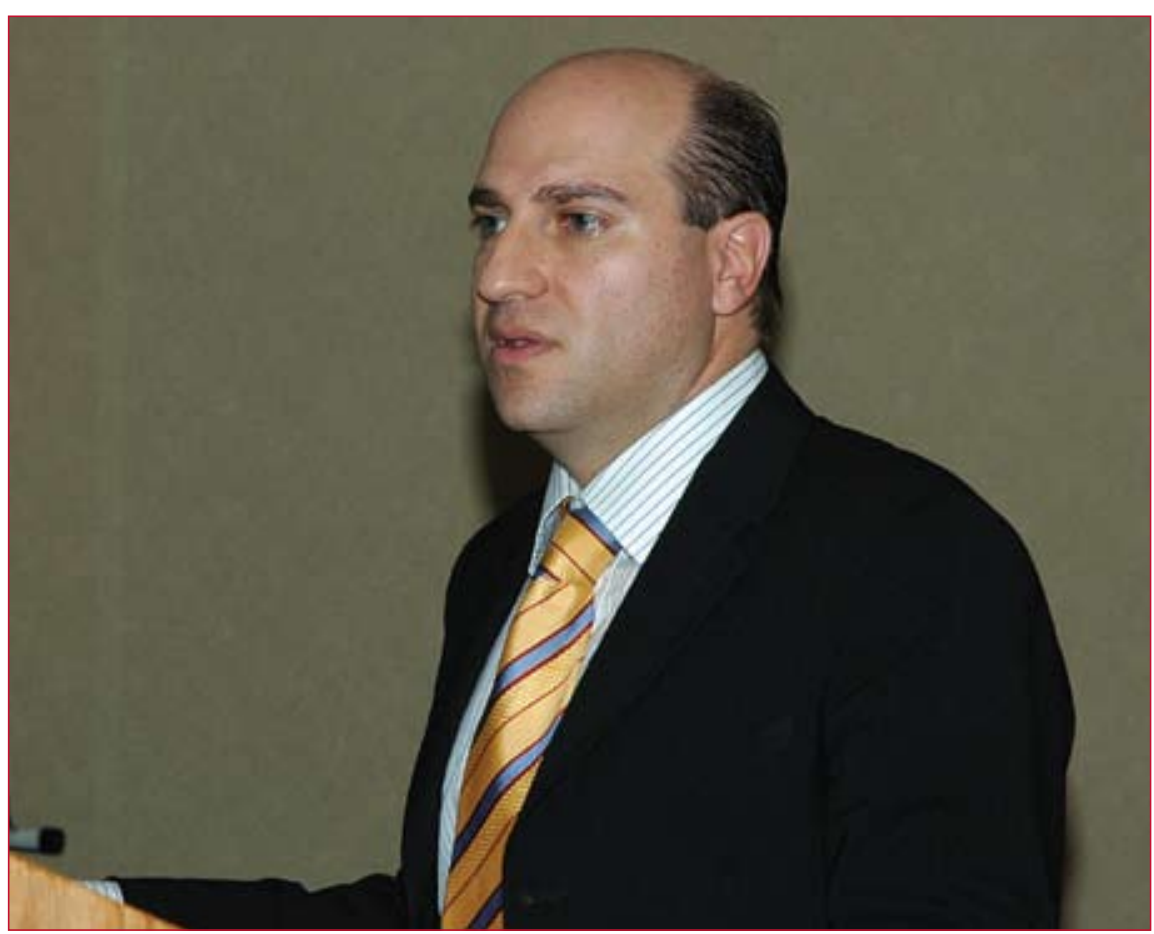

Stavros Nicolaou, chairman of the trade association, Pharmaceuticals Made in SA.

He added that previously, if the health minister (read TshabalalaMsimang) showed no interest in HIV drugs, that could be enforced via the director-general and 'they'd simply not feature as a priority'.

Legislation is being prepared to make the MCC a stand-alone, self-funded entity that will be fully functional within 2 years.

\section{The chairman of the trade association, Stavros \\ Nicolaou, estimated that a generic medicine market worth R1.2 billion could not be tapped into because of the delays.}

Speaking a fortnight after posting the letter, Venter said that top management within the MCC and the health department had recognised the urgency of the 'tender specific' issues, apologised and 'knew exactly what I was talking about'.

'I'm much happier now. They're trying to take control of the process,' he said.
The MCC's law enforcement division has also come under sustained fire for failing to stem the flood of 'snake doctors', continuing to blatantly offer bogus 'miracle' cures for various ailments, including HIV / AIDS.

The Democratic Alliance's Mike Waters said the 'days of AIDS dissidence' were gone, but the MCC had yet to catch up.

On its website the MCC boasts that over the past 5 years it has been 'transformed' in order to improve its performance and regulatory processes.

It states its main purpose as being 'to safeguard and protect the public through ensuring that all medicines that are sold and used in South Africa are safe, therapeutically effective and consistently meet acceptable standards of quality'.

That those premature claims come true within 2 years with an MCC having re-occupied its original mission, are two specific hopes shared by an entire country.

\section{Chris Bateman}

